\title{
Stress-strain state panel buildings and welded butt joints
}

\author{
Valery Lyublinskiy ${ }^{1,}$ and Andrzej Ubysz $^{2}$ \\ ${ }^{1}$ Moscow State University of Civil Engineering, Yaroslavskoe shosse, 26, Moscow, 129337, Russia \\ ${ }^{2}$ Wroclaw University of Science and Technology, Wybrzeze Wyspiańskiego,27, Wroclaw, Poland
}

\begin{abstract}
The constructive basis of a multi-story building is the spatial bearing system of buildings. In accordance with the chosen mathematical apparatus of the study, the spatial load-bearing system of a multi-storey building is a discrete vertical reinforced concrete structure formed by shear walls, and united by constant height connections with certain deformability. The above elements of the building support system provide strength, stability and durability of the structure as a whole. The spatial operation of the system is manifested in the fact that when loading one of its elements, other elements are included in the work. The purpose of the present study is to assess the influence shear bonds of the building's bearing system on its stress-strain state using a specific building.
\end{abstract}

\section{Introduction}

The bearing system of a multi-storey building consists of vertical structures united into a spatial system by vertical connections with certain flexibility. Vertical shear bonds such as concrete dowels, lintels, mortar welding and floor areas can be used as connections in a multi-storey building.

A discrete-continuous model was chosen as a mathematical model for bearing systems in multi-storey buildings [1-3]. A multi-storey building is modeled by a bunch of cantilever vertical elements and connected in space by bending and shear links - shear bonds. The discrete arrangement of vertical bearing elements is determined by the geometry of the building and the links connecting the whole building to the space system are replaced by continuous ones.

Usually, mathematical models of bearing systems of multi-storey buildings, in most cases, are oriented to the elastic operation of bearing elements and the bonds connecting them. In this case, they do not allow sufficient use of the reserves of strength of the entire bearing system or can distort the assessment of the real state of this bearing system of the building. The important feature of real work of bearing systems of buildings is nonlinear character of dependence between stress and deformation of both vertical bearing structures and elements connecting them. It should be noted that the forces (stresses) in all elements

*Corresponding author: 1va_55@mail.ru 
of the bearing system vary in height of the building. At high stress levels, changes are determined by concrete deformation diagrams, linking stresses with relative deformations, and shear bond deformation diagrams. And the higher the stress levels, the more significant these changes are.

The purpose of this work is to carry out a comparative analyse of the stress-strain state of bearing systems of multi-storey buildings on a concrete example of a panel building at linear and nonlinear deformation of vertical bearing structures and the bonds connecting them [4-6]. Shift connections in the form of jumpers and welding of mortgaged parts are considered. Shear bonds are the most stressed elements of the bearing system of a panel building. Thanks to them, the multi-storey building represents rather rigid and strong spatial system capable to resist vertical, horizontal and seismic loads, uneven deformations of the base, climatic temperature-humidity and emergency influences [7-9].

\section{Method}

According to the discrete-continuous model (figure 1) in the bearing system of a multistorey building discretely arranged the vertical shear walls are united by continuous height bonds, having certain flexibility.

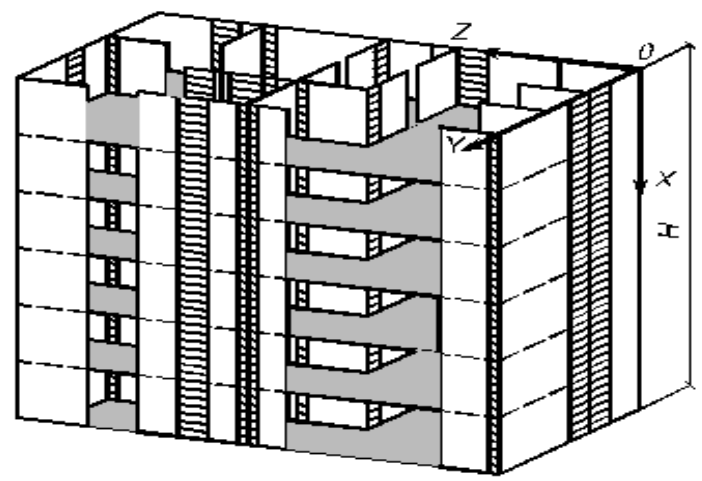

Fig. 1. The discrete-continuous model bearing system multi-story building.

The main task of the work is to fix changes in the tensely deformed state of the building, taking into account linear and nonlinear work of reinforced concrete and shear bonds, to estimate the influence of the main elements of the bearing system on the tensely deformed state of the building. Using discrete-continuous mathematical model, real diagrams of concrete deformation and shear bonds, it is possible to find out the real working conditions of the structural elements of the bearing system of a multi-storey building and the forces arising in them.

In this work the object of study was accepted 9-storey large-panel residential building of 125 series, consisting of one section. The bearing structures in the considered house are internal reinforced concrete panels, $160 \mathrm{~mm}$ thick of B20 class concrete. The external wall panels, $400 \mathrm{~mm}$ thick, are self-supporting. Depending on the location of the load-bearing elements, the load areas of each pole have been determined. The load is transferred to each pole by the load areas. Only the vertical load was applied to the load carrying system. The design of the building is shown in figure 2 . 


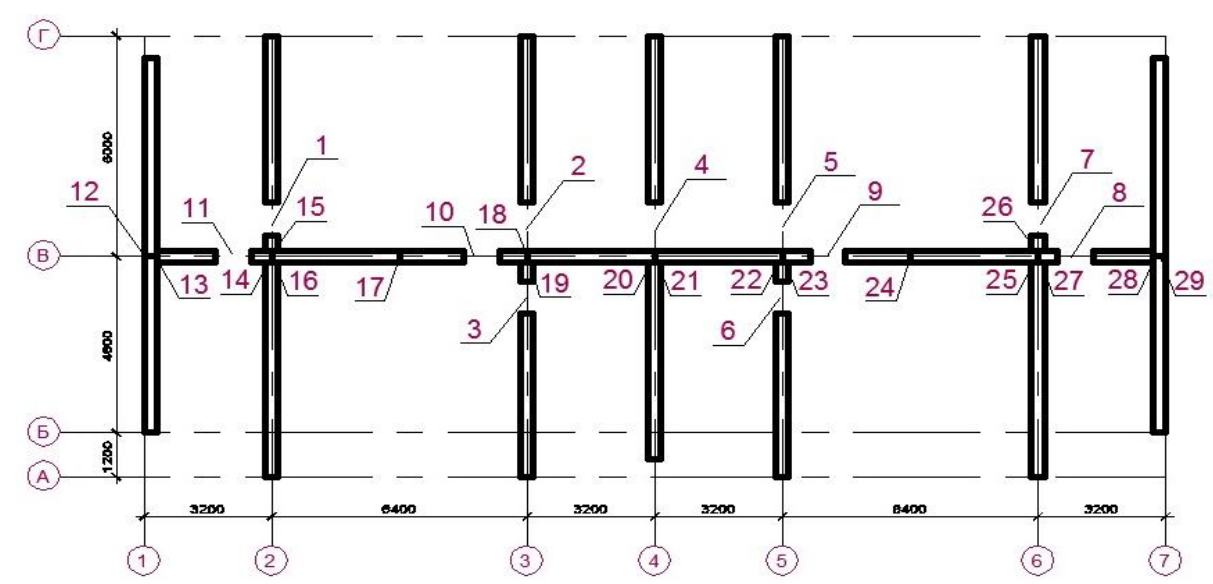

Fig. 2. The design scheme the building.

As a result of deformation of the carrier system under the influence of an external load, the bonds resist bending and shear. Shearing forces $\mathrm{Q}_{\mathrm{ii}}$ arise in them, which are balanced by the normal forces of $\mathrm{N}_{\mathrm{i}}$ arising in the load-bearing walls.

For an arbitrary $i$-shear wall of some spatial construction, we can write:

$$
N_{i}(x)=\sum_{j=1}^{n} \int_{0}^{x} Q_{i j}(x) d x
$$

The building's resistance to external load is described by the system of differential equations [2]:

$$
N^{\prime \prime}-R N=F
$$

where $N$ - matrix of unknowns, size $(m+1) \times n, \mathrm{~m}$ - number of vertical load-bearing elements; $\mathrm{n}$ - the number of design sections for the height of the supporting system; $\mathrm{R}$ square matrix of stiffness coefficients, size $(m+1) \times(m+1) ; F$ - load matrix, size $(m+1) \times n$.

The algorithm for calculating the spatial bearing systems of multi-storey buildings in a linear formulation was taken as the basis [3]. There are a large number of scientific publications on the nonlinear deformation of load-bearing elements of panel buildings in construction practice, but information on experimental data is limited. Various studies are devoted to the analysis of the work of shear bonds [10-12], welded embedded parts, vertical joints, horizontal joints and plate ties [13-14].

Many studies are devoted to the analysis of concrete deformation. A number of diagrams of concrete deformation under compression are included in design standards [1517]. For vertical reinforced concrete elements in this work, we used the transformed strain diagrams [18-20] obtained when testing cubic samples. The samples were tested using the universal hydraulic system WAW-500C in the strain control mode. For the lintels, the linear-piece deformation diagram "shear force Q - displacement $\Delta$ " presented in [21] was used.

Particular attention was paid to vertical butt welds as the main type of joint in panel buildings. The nonlinearity of the weld joint deformation was taken into account according to the deformation diagram "shear force Q - displacement $\Delta$ " obtained by the authors of [22-24] (figure 3). 


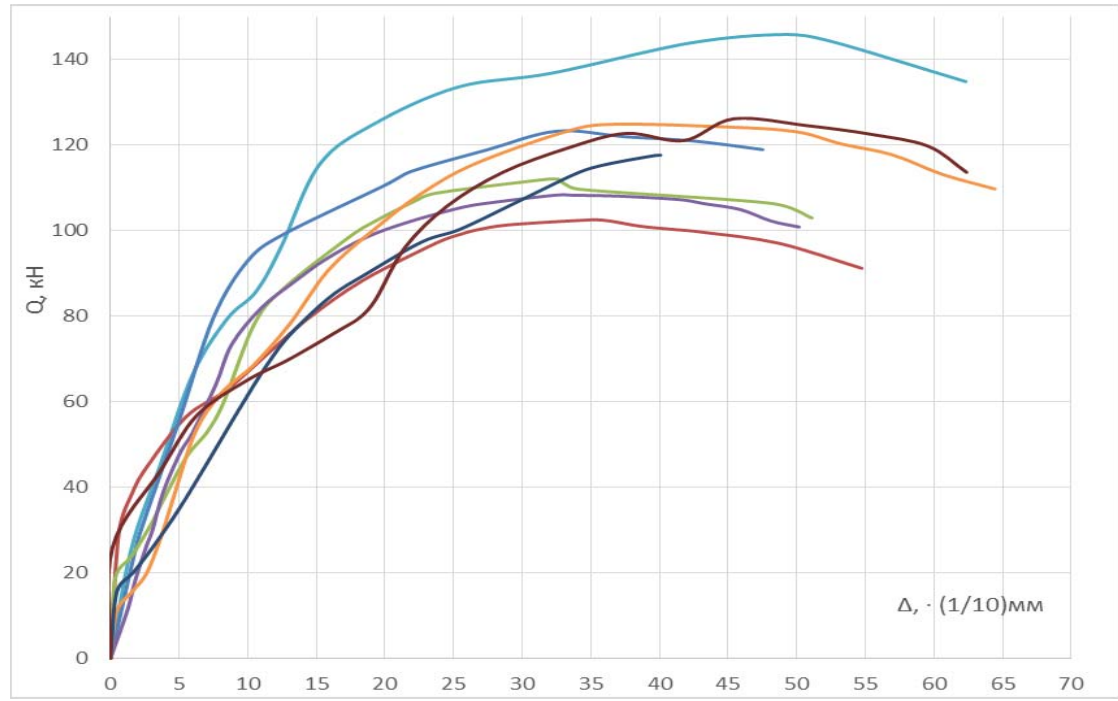

Fig. 3. Experimental diagram deformation Q- $\Delta$ for weld butt joints.

Wall panels in the 125 series were connected by welded butts. For the study, experimental designs were made, which exactly correspond to the type of vertical panel connection adopted in the design of large-panel buildings of this series. The samples were manufactured at the same enterprise that produced structures and erected large-panel buildings of the 125 series. To provide a shear force, each sample was crimped in two directions using metal plates on ties (figure 4).

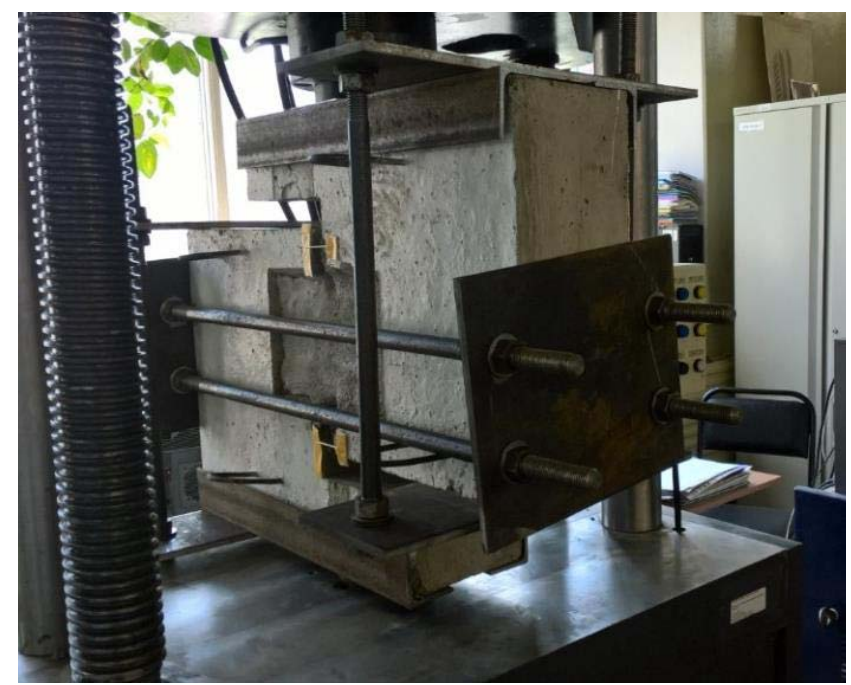

Fig. 4. Experimental welded butt.

A total of 8 samples were tested. Each sample was installed in a WAW-500C universal automatic hydraulic machine. The load was applied in stages. Each stage accounted for approximately $10 \%$ of the breaking load. At each stage, the sample was kept under load for at least 10 minutes. The loading rate was less than $0.5-2 \mathrm{~mm} / \mathrm{min}$. The following is installed (figure 5):

- deformation of the welded joints when working in shear is elastic-plastic; 
- at about 7-9 loading steps, the plate welded to the embedded part begins to collapse, which connects the two panels to each other;

- the plate butt joints is noticeably warped and begins to collapse;

- welded seams during loading did not show signs of destruction.

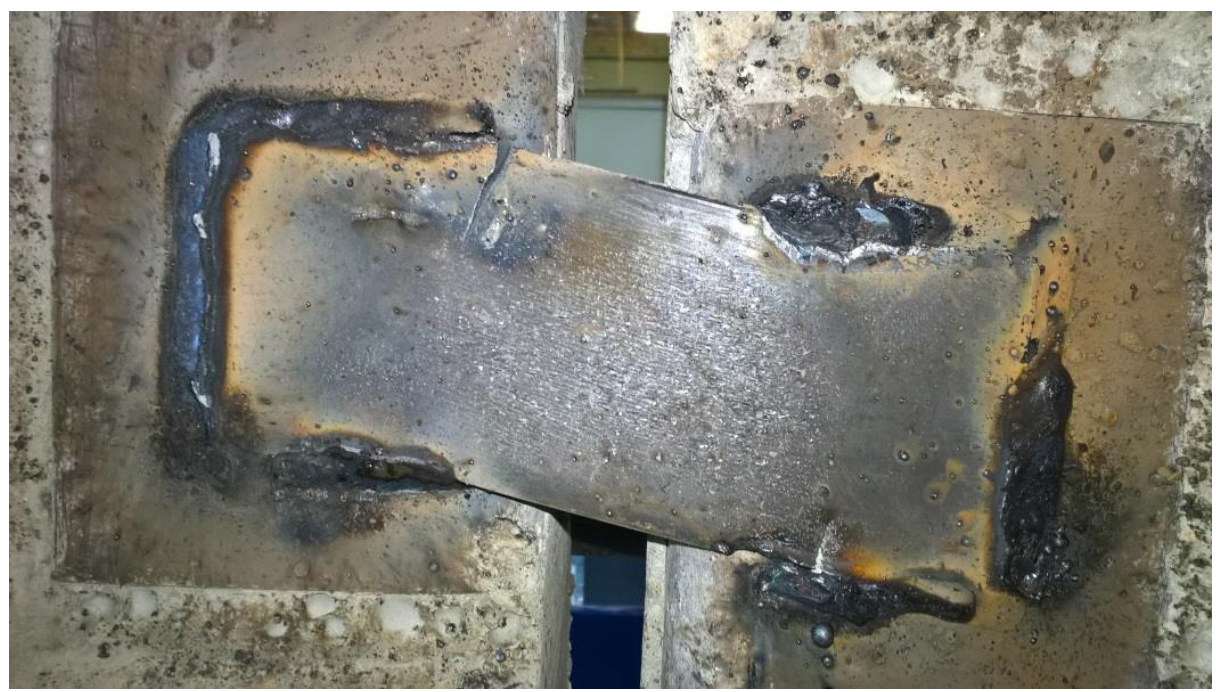

Fig. 5. Destruction of the connecting plate welded butt.

The nonlinear operation of vertical load-bearing elements in the algorithm was taken into account using concrete deformation diagrams and shear dependencies for shear bonds. In this case, an iterative process is performed, during which the main system of the discretecontinuum model is solved together with systems of equations that describe the nonlinear character of column deformation and shear relations.

$$
\left\{\begin{array}{l}
N^{\prime \prime}-R N=F \\
E=F(N) \\
S=F(N)
\end{array}\right.
$$

The nonlinear system that describes the change in the compliance of shear bonds:

$$
S=F(N),
$$

where: $S$ - shear bond deformability matrix, size $l \times k ; l$ - number of vertical shear bonds; $k$ - the number of intervals along the height of the building, within which deformability is constant. The nonlinear system that describes the change in the compliance of vertical contractions:

$$
E=F(N),
$$

where: $E$ - shear bond deformability matrix, size $i \times k$; i - number of vertical contractions; $\mathrm{k}$ - the number of intervals along the height of the building, within which deformability is constant.

Systems (2) and (3) are solved jointly by the sweep method and the iteration method. At each iteration, new values of the modulus of concrete panel buildings and rigidity of all shear bonds were introduced in accordance with the accepted experimental diagrams.

Since the system of nonlinear equations is not formulated explicitly, it is impossible to explicitly formulate the conditions for convergence. This is also due to the fact that the equilibrium condition of the building's building system is described by a system of second- 
order differential equations, and the "force - displacement", "stress - strain" dependencies can be represented by absolutely any mathematically dependencies, tabular data on the results of experiments.

Nevertheless, the accuracy of the numerical solution in this approach was compared on simply connected building systems with one row of vertical shear bonds, for which there is analytical dependence and the exact solution [1-2]. The error in the numerical solution did not exceed $5 \%$.

To improve the convergence process in the non-linear approach, the iteration method has been supplemented: the value of the S-flexibility adopted in the new calculation cycle is defined as a half sum of the previous and subsequent stages. The half-value method is used in conjunction with the sequential approximation method. Due to this, the possibility of the proposed iteration process inconsistency is excluded, which confirms the practice of the performed calculations.

\section{Results}

Under the influence of external load, there is a mutual shift in the shear walls, which is resisted by the bonds. Consequently, shear forces occur at the connection points of the bonds with the poles. As a result of research, we have constructed episodes of the distribution of shear forces on the example of two bonds - connecting the shear walls №20 and №15, №25 and №10 (figure 6). In the latter, there is a reduction in shear force by $22 \%$. In nonlinear modeling in some of vertical joints of the bearing system there is a $21 \%$ reduction in shear force, taking into account the deformation of the poles, and taking into account the deformation of welded joints - an increase of $13 \%$. In some connections significant changes are not observed.
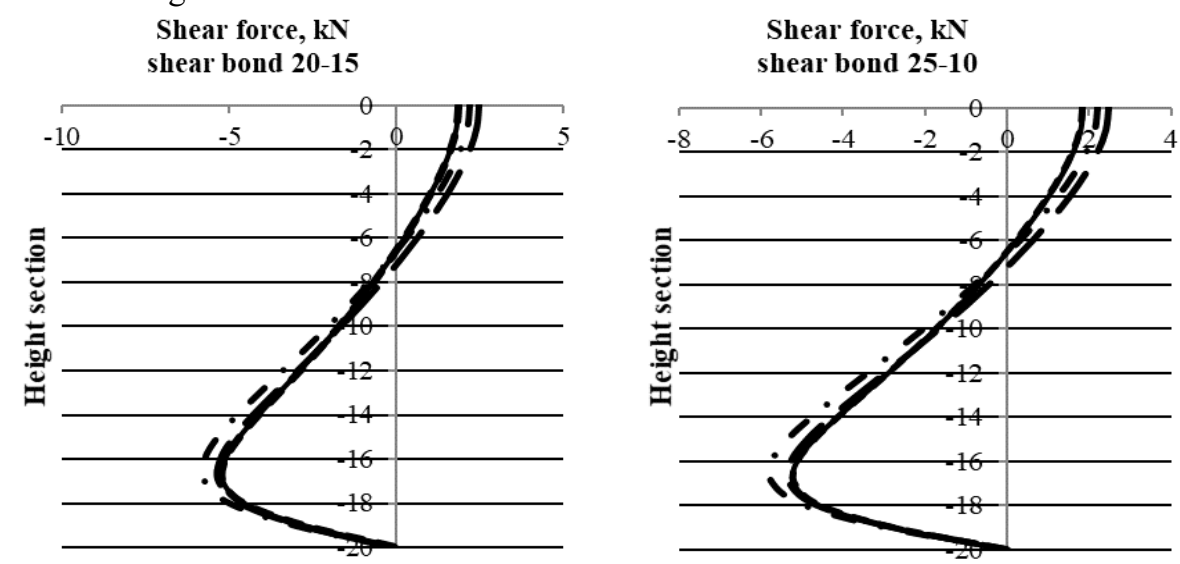

Fig. 6. Shear force diagram of shear bonds №20-15, №25-10 (dash-dot line -- calculation with diagrams of shear deformation, dashed line - calculation with diagrams of concrete deformation, continuous line - linear calculation).

Change of shear forces leads to change of normal compressive forces of walls, which were connected by these bonds (figure 7):

- in element № 16 normal forces increased by $26 \%$ taking into account nonlinear deformation of columns and decreased by $42 \%$ taking into account nonlinearity of welded joints;

- at the same time no significant changes are observed in element 25.

The account of nonlinearity of welded joints also leads to change of normal efforts:

- in pillar № 2 normal efforts increased by $20 \%$;

- in pillar № 28 - reduced by $10 \%$. 

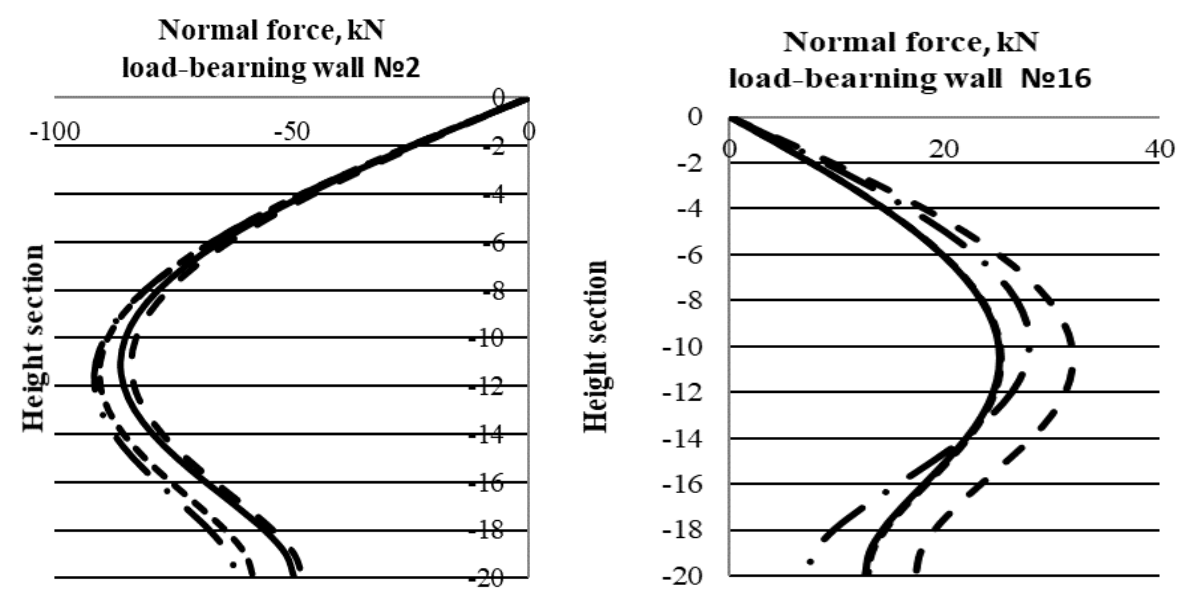

Fig. 7. Normal force diagram of load-bearing walls №№ 2, 16 (dash-dot line - calculation with diagrams of shear deformation, dashed line - calculation with diagrams of concrete deformation, continuous line - linear calculation).

\section{Discussion}

Point values of rigidity do not allow to get complete and reliable picture of the stress-strain state of structures, as they are a function of forces and stresses on the height of a multi-story building. Use of nonlinear diagrams of deformation of "shear - displacement" shear bonds and diagrams of "stress-strain" columns in discrete-continuous mathematical model introduces essential changes to the stress-strain state of the building's bearing system.

Consideration of nonlinear operation of bearing structures and shear bonds leads to a reduction of wall tensions. In some load-bearing elements the forces have remained unchanged taking into account deformation and concrete diagrams and shear bonds.

\section{Conclusions}

The issues of nonlinear deformation of panel buildings, in particular their nodal connections, are very important $[7,9,18]$. Constant stiffness values in terms of building height do not allow to get a complete and reliable picture of the stress-strain state of structures, as they are a function of forces and stresses in the height of a multi-storey building.

Deformability of vertical shear walls of the building is an essential factor in the assessment of the stress-strain state of structures. The use of nonlinear diagrams of deformation of shear-to-moving bonds and diagrams of stress-strain pillars in discretecontinuous mathematical model introduces significant changes to the stress-strain state of the bearing system of the building.

Consideration of nonlinear operation of bearing structures and shear bonds leads to a reduction of forces. In some load-bearing elements, the forces have remained unchanged, taking into account deformation and concrete diagrams and shear bonds. Non-linear modeling provides a better assessment of the stress-strain state of the spatial bearing system of the building. A greater influence on changes in tensions is made by taking into account the nonlinear deformation the shear links as opposed to taking into account the nonlinear operation of the shear bonds walls. 


\section{References}

1. P. Drozdov, Design and Calculation of Load-bearing Systems of Multi-storey Buildings and their Elements (Moscow: Stroyizdat) p 223, Russia (1977)

2. V. Lyublinskiy, J. Phys.: Conf .Ser. 1425, 012159 (2019)

3. V. Lyublinskiy, E. Veprikova, A. Astanin, Program Complex Analysis of Stressed Deformed State of Elements of a Multi-story Building (ABEC V 1.0.0.1): Certificate of official registration of a computer program № 2004612219 (Moscow: RosPATENT), (2004)

4. B. Sokolov, Y. Mironova, Hous. Constr. 5, pp 60-62 (2014)

5. A. Tamrazyan, D. Popov, MATEC Web of Conferences 117, 00162 (2017)

6. A. Tamrazyan, L Avetisyan, MATEC Web of Conferences 86, 01029 (2016)

7. F. Barbagallo, M. Bosco, A. Ghersi A, E. Marino, Eng. Struct. 229, 111622 (2021)

8. C. De Sousa, J. Barros, J. Correia, T. Valente, Constr. \& Build. Mat. 267, 120849 (2021)

9. S. Nyunn, F. Wang, J. Yang, J, Q. Liu, I. Azim, S. Bhatta, Structures 28, pp 1050-1059 (2020)

10. Y. Huang, E. Hamed, Z. Chang,S. Foster, J. Struct. Eng. 141, 004014143 (2015)

11. V. Blazhko, Hous. Constr. 3, pp 17-21 (2017)

12. G. Hong, C. Cooper, D. Lee, Eng. Struct. 32, pp 1341-55 (2010)

13. O. Dovzhenko, V. Pohribnyi, L. Karabash, Scien. \& Tech. 17, pp 146-56 (2018)

14. S. Arevalo, D. Tomlinson, J. of Build. Eng. 30, 101319 (2020)

15. C. Todut, D. Dan, V. Stoian, Eng. Struct. 80, pp 328-38 (2014)

16. S. Selamet, M. Garlock, Eng. Struct. 8, pp 2367-78 (2010)

17. D. Panfilof, A. Pischulev, K. Givadetdinov, Ind. \& Civ. Eng. 3, pp 80-84 (2014)

18. N. Karpenko, B. Sokolov, O. Radaykin, Ind. \& Civ. Eng. 1, pp 28-30 (2013)

19. V. Murashkin, G. Murashkin, MATEC of Web Conf. 196, 04008 (2018)

20. A. Granovsky, A. Dottuyev, V. Blazhko, Ind. \& Civ. Eng.1, pp 17-20 (2014)

21.SP 335.1325800.2017 Large-panel construction system. Design rules (Moscow: Ministry of Construction of Russia)

22. V. Lyublinskiy, M. Tomina, Syst. Technol. Met. 2, pp 153-58 (2018)

23. V. Lyublinskiy, M. Tomina, Syst. Technol. Met. 3, pp 154-58 (2018)

24. V. Lyublinskiy, Build. \& Reconst. 5, pp 17-22 (2019) 